\title{
A STUDY DONE IN PHASE 1 MBBS STUDENTS TO EVALUATE THE EFFECTIVENESS OF REMEDIAL INTERVENTION IN UNDERPERFORIMING STUDENTS OF BIOCHEIMISTRY.
}

KEY WORDS: Remedial teaching, poor performers, medical education
Ashika. M.S.

Col. (Dr) Vishal Marwaha*

Sumithra. N. Unni

Sajitha. Krishnan. P. P

Mrudula. E.V

\section{Sumitha Prabhu}

Reshmi. G. S.
Assistant Professor, Dept of Biochemistry, Amrita School of Medicine, Amrita ViswaVidyapeetham, Kochi, India.

Principal, Amrita School of Medicine, Amrita Viswa Vidyapeetham, Kochi, India. *Corresponding Author

Assistant Professor, Dept of Biochemistry, Amrita School of Medicine, Amrita Viswa Vidyapeetham, Kochi, India.

Professor\& HOD, Dept of Biochemistry, Amrita School of Medicine, Amrita Viswa Vidyapeetham, Kochi, India.

Lecturer, Dept of Biochemistry, Amrita School of Medicine, Amrita Viswa Vidyapeetham, Kochi, India.

Lecturer, Dept of Biochemistry, Amrita School of Medicine, Amrita Viswa Vidyapeetham, Kochi, India.

Lecturer, Dept of Biochemistry, Amrita School of Medicine, Amrita Viswa Vidyapeetham, Kochi, India.

Background: Remedial intervention or re teaching and repeat examination of the difficult chapters in Biochemistry can be one way to overcome weak performance by the phase 1 students in Biochemistry. The under performances by the medical students especially in Biochemistry may be because of inadequate guidance or lack of interest in a pre-clinical subject.

Methodology: The present study was a Quasi experimental study conducted among the under performers in biochemistry. In the second sessional examination results in Biochemistry, those students who got less than $50 \%$ marks and who were willing to participate in the study were enrolled for remedial intervention. After a pretest, the participants were divided into small groups. Later on, 4 core biochemistry topics were discussed as small group discussion for 20 minutes with these participants. Four separate topics were covered using the same methodology which was followed by a post test.The pretest and posttest scores were analysed statistically.

Results: In the present study a total of 54 students of first year MBBS (2018 batch) participated. The mean and standard deviation of the pre-test and post-test score was analysed statistically.P value was statistically significant.

Conclusion: In the present study the performance of the students after remedial intervention was good. So introduction of remedial intervention for re- teaching as part of medical curriculum by adjusting the teaching hours will help the medical students to handle their performance. The present study proves that targeted remedial intervention to the underperforming medical students after assessing their deficiencies can substantially improve their academic performance. Also we can conclude from the study the importance of early remedial intervention to these students. The success of remedial intervention can be augmented if the sessions are small group discussions.

\section{INTRODUCTION:}

Remediation or remedial intervention in medical education is 'the act of facilitating a correction for trainees who started out on the journey toward becoming a physician but have moved off course'. ${ }^{1}$ It can be defined as "additional teaching above and beyond the standard curriculum, individualized to the learner who without the additional teaching would not achieve the necessary skills for the profession". ${ }^{2}$ One of the necessary component of medical education is remediation which can ensure the performance as well as quality of the struggling learners. Remedial measures and follow up is still an inadequately addressed grey area in the field of medical education. Repeated poor performance always makes the students to be a burden to the medical school.

To address the learning difficulties, the remediation has been divided of different stages: 1) detecting problems, based on a subjective impression 2) gathering and documenting objective data, according to diagnostic hypotheses 3) making a pedagogical diagnosis based on this assessment and 4) planning a targeted remediation. In today's world, where failure in examination can drive a student to depression or to commit suicide, it is imperative that we take measures to prevent failures. Every effort can be made by the faculty of the department to analyse the difficulties faced by the students and provide necessary remedial measures. It is important that the medical educators intervene by identifying the under performance by the students as at times the phase 1 students find it difficult to identify the must learn areas of Biochemistry. The present study is conducted as there are limited studies undertaken to analyze the effect of remedial teaching on underperforming students or poor performing students.

\section{Research Question:}

Is remedial intervention effective for underperformers in Biochemistry, Phase 1 MBBS students?

\section{Hypothesis}

"Remedial intervention is an effective teaching method for underperformers in Biochemistry, Phase 1 MBBS students"

\section{OBJECTIVES:}

-To assess the effectiveness of remedial intervention on under performers in Biochemistry, Phase 1 MBBS students.

\section{METHODOLOGY:}

The present study was a Quasi-experimental (which is an interventional study that is used to estimate the impact of an intervention on a target population) study which was conducted in Amrita School of Medicine, AIMS, Kochi. 2018 batch MBBS students who got less than 50\% marks for their second sessional assessment participated in the study. A total of 54 phasel undergraduate students were included. The confidentiality of the students was maintained. The study duration was 2 months (July- August 2019). 


\section{INCLUSION CRITERIA:}

- Phase 1 MBBS students with less than 50\% marks in the second sessional examination.

- Those students who are willing to participate in the study after taking an informed consent.

\section{EXCLUSION CRITERIA:}

- Phase 1 MBBS students with less than $50 \%$ marks, who are not willing to participate and those who are absent on the days of data collection.

\section{Data Collection:}

Under performers in Biochemistry were identified from the second sessional examination results wherein all students who got less than $50 \%$ marks and who were willing to participate in the study were enrolled for remedial inervention. After taking an informed consent (Annexure I) from these students, a pre test (MCQs) ((Annexure II)) was conducted. Four biochemistry topics, from the must know (core) areas, were taught as small group discussions (SGD) by dividing them further into small groups. Similar four sessions were conducted for 20 minutes per topic after their regular class for 20minutes per topic. The students were enthusiastic Post interventional assessment was done using MCQs. The pre test and post test marks were compared statistically and analysed.

\section{Statistical Analysis:}

Statistical analysis was done using the software IBM SPSS statistics 20. Paired Student's t test was applied to compare the mean of the marks scored. A $p$ value of $\leq 0.05$ was considered as statistically significant.

\section{Ethics Approval:}

Permission for the study was given by the Principal, Amrita School of Medicine, AIMS. Ethics approval was given by the Institutional Ethics Committee, AIMS, Kochi.

\section{RESULTS:}

A total numbers of 54 students out of 100 failed to secure $50 \%$ in their second sessional /internal examination. These 54 students were included in the study. The mean and standard deviation was analysed statistically for pretest and posttest scores and the pvaluewas statistically significant (Table l \&figure l).

Table 1: Mean And Standard Deviation Of The Pre Test And Post Test Scores:

\begin{tabular}{|l|l|l|l|l|}
\hline & N & Mean & SD & p value* \\
\hline Glycolysis- pretest & 54 & 4.03 & 1.72 & 0.000 \\
\hline Glycolysis- posttest & 54 & 4.40 & 0.96 & 0.000 \\
\hline Cholesterol- pretest & 54 & 4.00 & 1.73 & 0.000 \\
\hline Cholesterol- posttest & 54 & 8.53 & 1.17 & 0.000 \\
\hline Isoenymes- pretest & 54 & 3.50 & 1.50 & 0.000 \\
\hline Isoenymes- posttest & 54 & 8.05 & 1.32 & 0.000 \\
\hline C.I- pretest & 54 & 2.90 & 1.45 & 0.000 \\
\hline C.I- posttest & 54 & 7.94 & 1.29 & 0.000 \\
\hline
\end{tabular}

C.I $=$ competitive inhibition

* $p$ value statistically significant

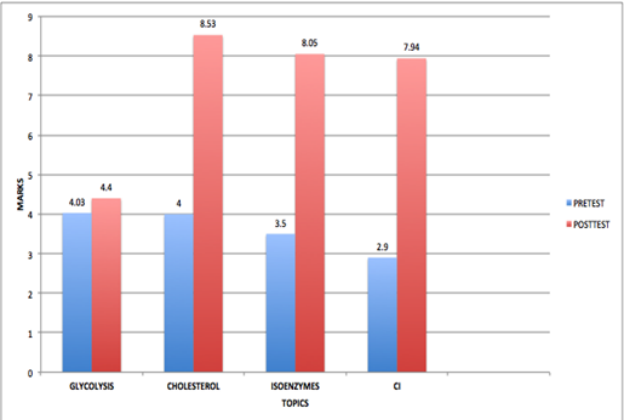

Figure 1: Mean And Standard Deviation Of The Pre Test And Post Test Scores:

\section{DISCUSSIONS:}

It has been noted that remedial intervention is effective in the improvement of underperforming students. This study attempts to find out whether remedial intervention is effective in the underperforming phase 1 students in Biochemistry. The study was conducted among the Phase 1 undergraduate medical students for a period of 2 months.

The mean and standard deviation of the pretest and posttest score on the topic glycolysis was $4.03 \pm 1.72$ and $4.40 \pm 0.96$ respectively and was statistically significant. The mean and standard deviation of the pretest and posttest score on the topic cholesterol synthesis was $4.00 \pm 1.73$ and $8.53 \pm 1.17$ respectively and was statistically significant. The mean and standard deviation of the pretest and posttest score on the topic isoenzymes was $3.50 \pm 1.50$ and $8.05 \pm 1.32$ respectively. It was statistically significant. Lastly the mean and standard deviation of the pretest and posttest score on the topic competitive inhibition was $2.90 \pm 1.45$ and $7.94 \pm 1.29$ respectively and was statistically significant. (Table 1 and Figure 1).

Our study showed improvement in the post test scores after the remedial intervention which was similar to the studies done on remedial intervention. ${ }^{7,8}$ This is an important finding because as medical educators, one should re-teach the chapters which are difficult for the students to understand. One of the main problems of under performance in Biochemistry by the phase 1 students may be difficulty to understand the cyclic pathways along with their clinical relevance. Repeat examinations may also be conducted as a remedial intervention, whenever needed. Teacher-student interactions were enhanced in the smaller group re-teaching as the number of students was less. This indeed is helpful to prevent the failure cycle by the students especially in phase 1 . There are very limited studies which had analysed the effect of remedial intervention or re-teaching on underperforming undergraduate medical students.

\section{Limitations OfThe Study:}

The study was conducted in a small sample size because of limited time.

\section{CONCLUSIONS AND RECOMMMENDATIONS:}

In the present study, the performance of the students after remedial intervention was good among the participants. So, introducing remedial intervention or re-teaching as part of medical curriculum by adjusting the teaching hours will help the medical students in handling their performance. Reteaching can improvise the failure rate, enable them to understand a pre-clinical subject which is the founding stone of clinical subjects in subsequent years of medical education.

FUNDING: No funding was involved in this study.

CONFLICT OF INTEREST: No conflict of interest.

ACKNOWLEDGMENTS: I am grateful to the contributions by the Biochemistry dept and my institution (AIMS) towards the study.

\section{REFERENCES:}

1. Kalet A, Chou CL. Remediation in medical education. New York: Springer; 2014.p.xvii.

2. Guerrasio J, Garrity MJ, Aagaard EM. Learner deficits and academic outcomes of medical students, residents, fellows, and attending physicians referred to a remediation program, 2006-2012. Acad Med. 2014 Feb;89(2):352-8.

3. Ray (Arora) Suranjana, Ray Ujjani, Ray Manas Kanti. Peer Tutoring as a Remedial Measure for Slow Learners in a Medical School. JKIMSU. 2015 JanMar.Vol. 4,No. 1 .

4. Manisha Das, Somnath Maity, Soma Gupta, Aparna Mondal, Sanat Kumar Dolui, Prithwijit Banerjee. Performance Improvement in Examination by ReTeaching the Underperforming Undergraduate Medical Students. International Journal of Pharmaceutical and Medicinal Research. Int.J.Pharm. Med.Res. 2015;3(3):242-245

5. Heather Ridinger,Jamie Cvengros, James Gunn, Pedro Tanaka,Joseph Rencic. Struggling Medical Learners: A Competency-Based Approach to Improving Performance.2018 August 15;10.15766/mep_2374-8265.10739.

6. Christian Gray, Nick Toms. A holistic remediation intervention for struggling 
undergraduate medical students affords sustained Progress Test performance recovery. : https://doi.org/10.15694/mep.2018.0000210.1

7. Cleland J, Mackenzie RK, Ross S, Sinclair HK, Lee AJ. A remedial intervention linked to a formative assessment is effective in terms of improving student performance in subsequent degree examinations. Medical Teacher 2010. 32:85-90.

8. Sayer M, Chaput de SM, Evans D,Wood D. Support for students with academic difficulties, Medical education 2002.36:7:643-50. 